Original Research Article

\title{
Evaluating the effects of Moringa oleifera on atherogenic lipoprotein indices of HIV infected Nigerian adults on tenofovir-based antiretroviral regimen
}

\author{
Chinwe F. Anyanwu' ${ }^{1}$, Wolie A. Obianime ${ }^{1}$, Iyeopu M. Siminialayi ${ }^{1}$, Eric O. Aigbogun²*
}

\begin{abstract}
${ }^{1}$ Department of Pharmacology, ${ }^{2}$ Department of Anatomy, University of Port Harcourt, Rivers State, Nigeria
\end{abstract}

\section{Received: 24 March 2019 \\ Revised: 08 April 2019 \\ Accepted: 03 May 2019 \\ *Correspondence to: \\ Dr. Eric O. Aigbogun, \\ Email: \\ eric_aigbogun@uniport.edu.ng}

Copyright: (C) the author(s), publisher and licensee Medip Academy. This is an openaccess article distributed under the terms of the Creative Commons Attribution NonCommercial License, which permits unrestricted noncommercial use, distribution, and reproduction in any medium, provided the original work is properly cited.

\begin{abstract}
Background: The administration of tenofovir (TDF) based (tenofovir/ lamivudine/efavirenz) antiretroviral regimen for the management of HIV has remained a concern to both clinicians and patients, thus necessitating the need for suitable supplement for the management of ART induced metabolic abnormalities. The study evaluated the effects of Moringa supplementation on the atherogenic lipoprotein indices of HIV patients on TDF-based regimen at the University of Port Harcourt Teaching Hospital, Rivers State, Nigeria.

Methods: The study was designed as a time dependent investigation structured into 3 visits, visit 1 (cross sectional, baseline), visit 2 (4 weeks after administration) and visit 3 (12 weeks post administration). Subjects recruited (140) into this study comprised of two groups, TDF-M ( $\mathrm{n}=56$, administered Moringa Supplement) and TDF-NM ( $\mathrm{n}=84$, no supplement).

Results: At baseline, more than $50 \%$ of the patients had at least one abnormal atherogenic lipoprotein indices (Log $(\mathrm{TC} / \mathrm{HDL}-\mathrm{C})=85.7 \%, \mathrm{TC} / \mathrm{HDL}-\mathrm{C}=58.5 \%$ and LDL-C/HDL-C $=51.4 \%$ ), although at lower limits. At the end of 12 weeks of Moringa supplement administration, the results showed subjects in the TDF-M group who were at risk of CVD had fallen to $20 \%$, indicating a dramatic $(40.4 \%)$ decrease, while the prevalence of TDF-NM subject at risk of CVD rose to $53.6 \%$ $\left(\chi^{2}=26.67, \mathrm{P}<0.001\right)$. HIV patients on TDF-based regime, who were at risk of CVD had elevated triglycerides and low-density lipoprotein cholesterols which inversely affected the levels of high-density lipoprotein and negatively impacting the atherogenic indices.
\end{abstract}

Conclusions: Moringa oleifera supplementation may be helpful in ameliorating the metabolic abnormalities associated with HIV patients on TDF-based regimen.

Keywords: Human immunodeficiency viruses, Tenofovir disoproxil fumarate, Metabolic abnormalities, M. oleifera

\section{INTRODUCTION}

Complications associated with Human Immunodeficiency Virus (HIV) infection since it was first reported has become a global issue worthy of research. ${ }^{1}$ Newer complications are emerging frequently, which poses as therapeutic challenges for the clinicians. ${ }^{1}$ Following the introduction of combination ART such as the tenofovir (TDF) based (tenofovir/lamivudine/efavirenz) antiretroviral regimen, there is great concern among patients using and clinician administering these regimens. ${ }^{1-3}$ More concerns have emerged following the increased prevalence of fat redistribution, central obesity, and visceral abdominal lipoaccumulation, and lipoatrophy. ${ }^{3-5}$ In addition to the changes in fat disorder, other metabolic abnormalities identified in patients on combination ART included the disorder of lipoprotein metabolism, diabetes, irresponsiveness to insulin, and steatohepatitis. ${ }^{6}$ Evidence from calculations, analysis, and modelling of cardiovascular risk factors such as stroke, 
myocardial infarctions (MIs), and sudden cardiac death have cumulatively strengthened these findings, suggesting that cardiovascular diseases have surfaced as a significant cause of death in HIV-infected patients. , $^{37-9}$

The atherogenic plasma index, the logarithm of the ratio of plasma concentration of triglycerides to HDL-cholesterol (Log (TG/HDL-C)) have been extensively studied and shown to correlate with cholesterol esterification rates in apoB-lipoprotein-depleted plasma (FER(HDL)) and lipoprotein particle size, thus finding relevance in its use as a biomarker of plasma atherogenicity in the establishment of cardiovascular risk. ${ }^{10,11}$ Evidences based on several observational studies, including the Framingham, the Prospective Cardiovascular Münster (PROCAM) and the Lipid Research Clinics Program (LRCP) suggests that total cholesterol (TC) to HDL cholesterol ratio is a more powerful coronary risk predictor than independently used TC, LDL cholesterol and HDL cholesterol, either solely or in combinations. ${ }^{12-14}$ In a multivariate analysis conducted by WOSCOPS, AFCAPS/TexCAPS and $4 S$ study suggested that atherogenic lipoprotein indices have higher predictive value for the development of coronary events when compared to other lipid parameters. ${ }^{15-17}$

From the experimental investigation, $M$. oleifera reduced dyslipidemia, normalizes the activities of myocardial marker enzymes and possess cardiac protective qualities. ${ }^{18,19}$ Therefore this study investigated the effect of known, acceptable supplement $(M$. oleifera $)$ on atherogenic lipoprotein indices, in other to assess its mitigating qualities in HIV patients.

\section{METHODS}

Prior to the study, ethical clearance was obtained from the Research Ethics Committee of the University of Port Harcourt, Nigeria and this was approved with reference number UPH/R\&D/REC/04. The study was conducted in line with the current Revised CIOMS (Council for International Organization of Medical Sciences) International Ethical Guidelines and other relevant regulatory requirements were strictly adhered to. ${ }^{20}$ Informed consents were obtained from all volunteer subjects recruited into the research.

\section{Study area}

This study was carried out at the HIV clinic of the Outpatient Department of the University of Port Harcourt Teaching Hospital, Port Harcourt, Nigeria.

\section{Study population}

The subjects were drawn from the population of HIV patients on ART attending the medical out-patient clinic in UPTH, Port Harcourt, Nigeria which serves as a regional center for the management of HIV patients.

\section{Study design}

This study was designed as a Longitudinal Randomized Comparative Trial (LRCT) carried out from February 2016 to May 2016. This type of research design is used in clinical practice when patients will require some form of treatment allocated to one or more groups over time. The groups represent the different treatments under study. This study design is in-part an FDA/WHO phase II classification of randomized controlled clinical trials during drug testing. However, it has been clarified by DFA/WHO that the essence of a controlled clinical trial is not to "discover" a new drug or therapy, rather, to affirm or refute unverifiable clinical impressions, and to define in a scientific way the extent (effectiveness and limitations) of the drugs. ${ }^{21}$

\section{Patient recruitment and sample size determination for Randomized Comparative Trial (RCT)}

The sampling technique was adopted from the model of Schulz KF et al. ${ }^{22}$ With some modification to fit purpose (Figure 1) and sample sizes ranging from 100 to 200 participants. $^{21}$

\section{Eligibility and enrollment}

Eligibility was dependent on conformance to the set minimum requirements stated in the inclusion criteria and enrollment procedure was in line with the RCT model as established by Schulz KF et al, Chalmers TC et al, and Ranjith G. ${ }^{22-24}$

\section{Administration of Moringa supplement}

This research was designed as a time-dependent comparative study with two groups. Group 1 consisted of HIV patients administered the test drug (M. oleifera supplement) tagged ART-M and group 2 were HIV patients on anti-retroviral therapy alone, designated ARTNM. The supplements were administered from the day after the baseline data (visit 0) were obtained through 12 weeks, and assessment was in line with the design in Figure 1.

Biological samples were obtained as indicated in the three visits, baseline (commencement), 4 weeks follow-up, and 12 weeks post commencement of supplements (end of study). The study design allowed for differential comparative analysis of the biological parameters of the group to determine the effects of Moringa supplement on atherogenic lipoprotein indices such as Log (TG/HDL-C), TC/HDL-C and LDL/HDL-C.

\section{Sample size determination (analysis phase)}

The sample size was determined using the superiority design by Li LM et al, and Zhong B. ${ }^{25,26}$ 


$$
\mathrm{N}=2 \times\left(\frac{\mathrm{Z}_{1-\frac{\alpha}{2}}+\mathrm{Z}_{1-\beta}}{\delta}\right)^{2} \times \mathrm{S}^{2}
$$

Where,

- $\mathrm{Z}_{\alpha}=0.05$ at $95 \%$ confidence desired (two tailed test $)=1.96$.

- $\quad \mathrm{Z}_{\beta}=$ power to detect such a difference (set at $80 \%$ ) with a $20 \%$ withdrawal rate $=0.84$.

- $\delta=$ difference to be detected in the percentage change $=5$.
- $\quad S^{2}=$ Polled standard deviation of both comparison $=15^{2}=225$.

Using the above data,

$$
\mathrm{N}=2 \times\left(\frac{1.96+0.84}{5}\right)^{2} \times 15^{2}
$$

$\mathrm{N}=140$ (minimum sample size for the study).

The sample sizes per stratum were equally allocated at the end of visit 2 , since the experimenting population is above the required sample size.

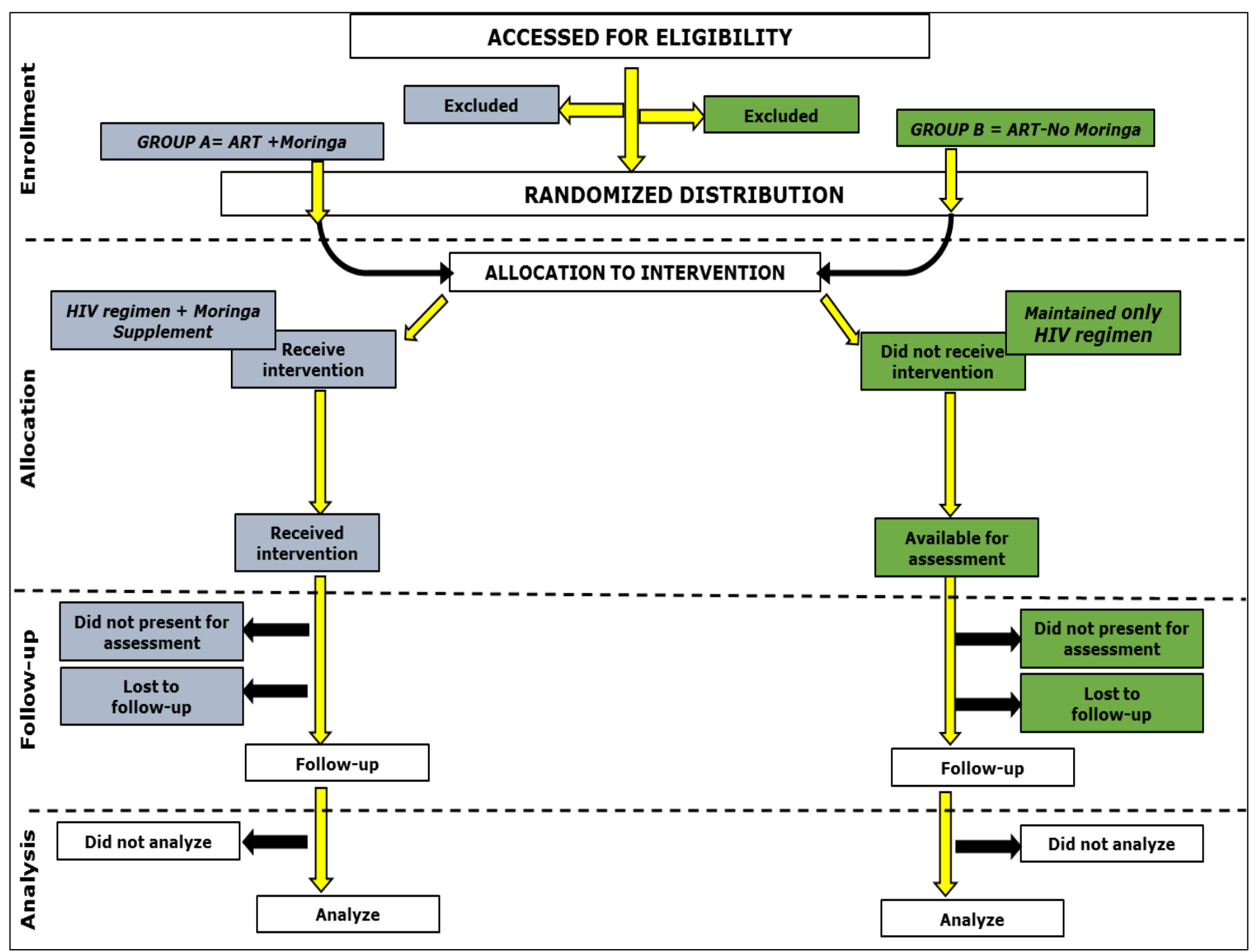

Figure 1: Schulz et al, model for random comparative trail with modifications. ${ }^{22}$

\section{Inclusion/exclusion criteria}

The inclusion criteria included subjects must be HIV positive and on ART for at least 3 months and not terminally ill, within ages 18 to 55 years, with the ability to give informed consent and not on any herbal, traditional or complementary medicine in the last 2 weeks prior to the commencement of the study. Excluded subjects were HIV patients above or below the set age limits, unable to give informed consent or severely ill patients and those who are pregnant or planning to be pregnant within the next 4 months. 


\section{Data (sample) collection}

Study participants were randomly assigned to groups and their venous blood samples were obtained after they duly signed the consent form. The blood was analysed in the HIV research lab within the premises, a physician attended to the participants at each follow-up visit to ascertain the level of compliance.

\section{Instrumentation/sample analysis}

Samples were analysed in the research laboratory of the University of Port Harcourt Teaching Hospital (UPTH), Port Harcourt, Nigeria using the clinical chemistry analyser (VS10) manufactured by Vitro Scient. The machine utilises the operational principle guided by Beerlambert's law (i.e. the linear relationship between absorbance and concentration of an absorbing species).

\section{Determined parameters}

The study design allowed for differential comparative analysis of the biological parameters of the group to determine the effects of Moringa supplements on cardiac risk factors such as BMI, lipid profile and atherogenic index (Log (TC/HDL-C), TG/HDL-C.

The categorization of the atherogenic lipoprotein indices for deviation from normal range was assessed using values provided by Dobiásová $\mathrm{M}$ and Nwagha $\mathrm{U}$ et al. ${ }^{10,27}$

- TC/HDL cholesterol ratio- For example, if a person has total cholesterol of $200 \mathrm{mg} / \mathrm{dL}$ and an HDL cholesterol level of $50 \mathrm{mg} / \mathrm{dL}$, the cholesterol ratio is 4.0 , however, it is important to keep the ratio below 5.0 , the optimum ratio is 3.5 .

- LDL/HDL cholesterol ratio- apart from TC/HDL, the proportion of HDL/LDL can also be used. For example, if a person has an LDL of $140 \mathrm{mg} / \mathrm{dL}$ and an HDL cholesterol level of $40 \mathrm{mg} / \mathrm{dL}$, the HDL/LDL ratio is 0.3 , however, it is important to keep the ratio above 0.3 , the

- Optimum ratio is 0.35 or close to 0.4 . If the reverse is used (LDL/HDL) the ratio is 3.5. Therefore, it is of clinical importance to maintain the ratio below 3.5.

- $\quad \log$ (TG/HDL): $\log$ (TG/HDL) of -0.3 to 0.1 is associated with low, 0.1 to 0.24 with medium and above 0.24 with high $\mathrm{CV}$ risk.

Analysis was carried out using SPSS (IBM® version 3) and XLSTAT (4.0.1, 2015). Summary statistics were performed (continuous data were represented as mean (S.D) while frequency (\%) for all categorical data) to compare changes. Adjusted t-test and Chi-square analysis of association were used to determine the differences in the distribution.

\section{RESULTS}

At the end of the enrollment, complete data were obtained

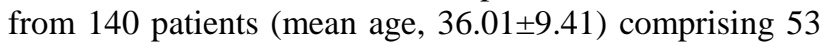
males (mean age, $39.11 \pm 10.46$ ) and 87 females (mean age $35.63 \pm 8.33)$. The BMI of males $\left(23.77 \pm 3.26 \mathrm{kgm}^{-2}\right)$ and females $\left(24.79 \pm 4.60 \mathrm{kgm}^{-2}\right)$ patients were statistically indifferent $(\mathrm{P}>0.05)$.

The mean $( \pm$ SEM) atherogenic index $(\log (\mathrm{TG} / \mathrm{HD}))$ of HIV patients on TDF taking moringa supplement (TDF-M) and those not taking the supplement (TDF-NM) at visit 0 (baseline) were $0.02 \pm 0.03$ and $-0.02 \pm 0.03$, at visit 1 (4 weeks after administration) was $0.009 \pm 0.03$ and -0.044 \pm 0.03 respectively, while at visit 2 (end of 12 weeks administration) was $-0.14 \pm 0.04$ and $-0.11 \pm 0.03$ respectively. The mean $( \pm$ SEM) values for lipogenic ratios (TC/HDL and LDL/HDL) were as follows, at visit 0 , TC/HDL (TDF-M=3.60 \pm 0.18 , TDF-NM=3.60 \pm 0.19 ) and LDL/HDL (TDF-M=2.05 \pm 0.15 , TDF-NM=2.05 \pm 0.17 ).

Table 1: Descriptive characteristics of atherogenic lipid indices of the HIV patients on ART at the various visits.

\begin{tabular}{|c|c|c|c|c|c|}
\hline \multirow{2}{*}{ Regimen } & \multicolumn{5}{|c|}{ Atherogenic lipid indices (Mean \pm S.E.) } \\
\hline & Visit 0 (Baseline) & Visit 1 (4 we & dmin.) & Visit $2(12 \mathrm{w}$ & s admin.) \\
\hline \multicolumn{6}{|c|}{ Log (TG/HDL) } \\
\hline TDF-M & $0.02 \pm 0.03$ & $0.009 \pm 0.03$ & Decrease & $-0.14 \pm 0.04$ & Decrease \\
\hline TDF-NM & $-0.02 \pm 0.03$ & $-0.044 \pm 0.03$ & Decrease & $-0.011 \pm 0.03$ & Increase \\
\hline \multicolumn{6}{|c|}{ TC/HDL } \\
\hline TDF-M & $3.60 \pm 0.18$ & $3.53 \pm 0.17 *$ & Decrease & $3.15 \pm 0.26^{*}$ & Decrease \\
\hline TDF-NM & $3.60 \pm 0.19$ & $3.40 \pm 0.15$ & Decrease & $3.74 \pm 0.57$ & Increase \\
\hline \multicolumn{6}{|c|}{ LDL/HDL } \\
\hline TDF-M & $2.05 \pm 0.15$ & $2.13 \pm 0.20$ & Increase & $1.42 \pm 0.15 *$ & Decrease \\
\hline TDF-NM & $2.05 \pm 0.17$ & $1.86 \pm 0.12$ & Decrease & $1.85 \pm 0.11$ & Decrease \\
\hline
\end{tabular}

$\mathrm{TC}=$ Total cholesterol, $\mathrm{TG}=$ Triglyceride, $\mathrm{HDL}=$ High density lipoproteins, $\mathrm{LDL}=$ Low density lipoproteins, $\mathrm{C}=\mathrm{Cholesterol}, \mathrm{S} . \mathrm{E}=\mathrm{Standard}$ error of mean. *Significant at $\mathrm{P}<0.05$ 
At visit 1, TC/HDL $\quad(\mathrm{TDF}-\mathrm{M}=3.53 \pm 0.17, \quad$ TDF$\mathrm{NM}=3.40 \pm 0.17)$ and LDL/HDL (TDF-M=2.13 \pm 0.20 , TDF-NM=1.86 \pm 0.12 ). At the end of visit $2, \mathrm{TC} / \mathrm{HDL}$ (TDF-M=3.15 \pm 0.26 , TDF-NM=3.74 \pm 0.57 ) and LDL/HDL $(\mathrm{TDF}+\mathrm{M}=1.42 \pm 0.20, \quad \mathrm{TDF}-\mathrm{NM}=1.85 \pm 0.11)$. Significant differences were observed in TDF-M and TDF-NM groups were observed for TC/HDL at visit 1 and 2 and LDL/HDL at visit $2(\mathrm{P}<0.05)$. All other differences observed in the parameters were statistically insignificant across the various visits $(\mathrm{P}>0.05)$ (Table 1$)$.

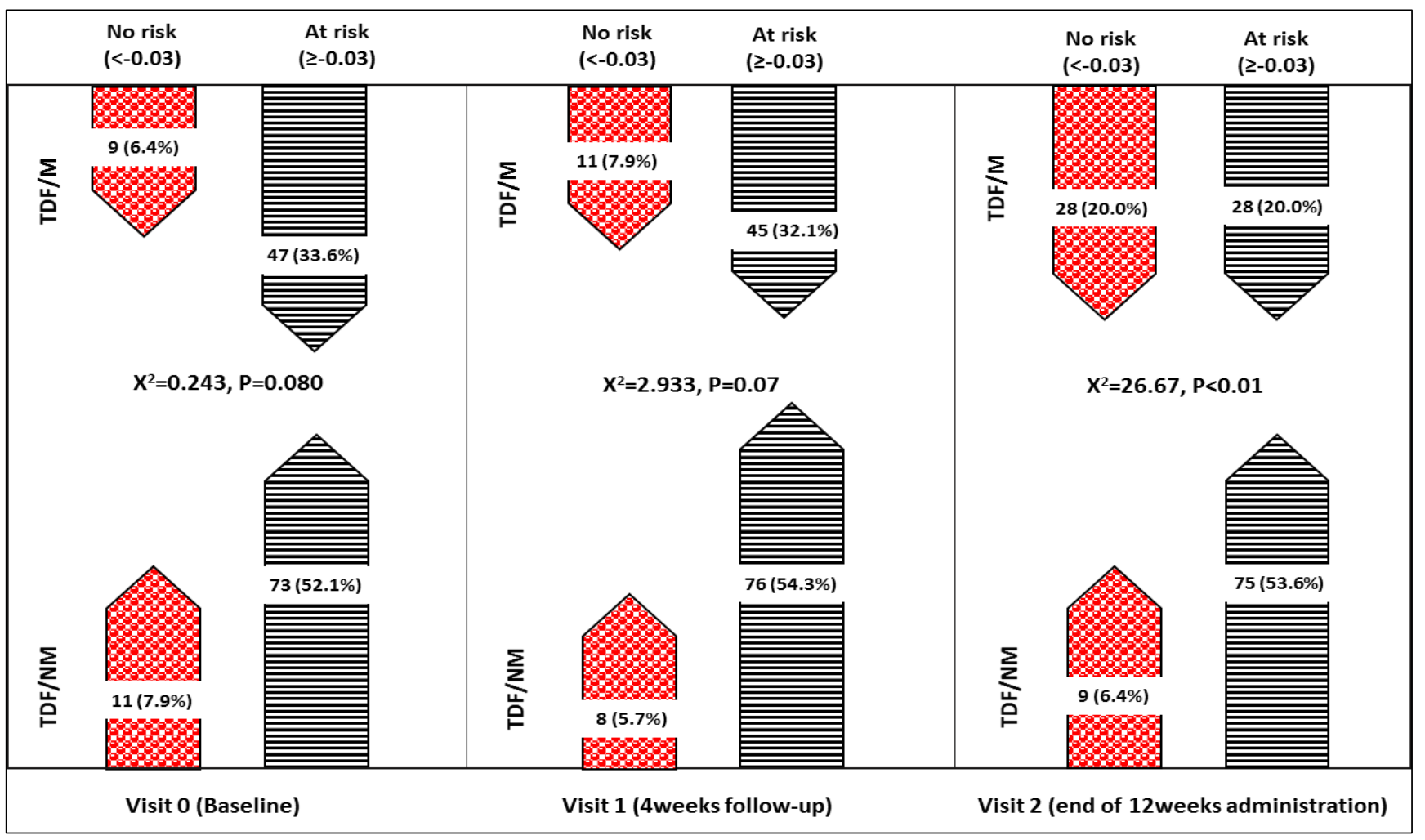

Figure 2: Log (TG/HDL) cut off distribution of HIV patients on TDF-M and TDF-NM at the various visits.

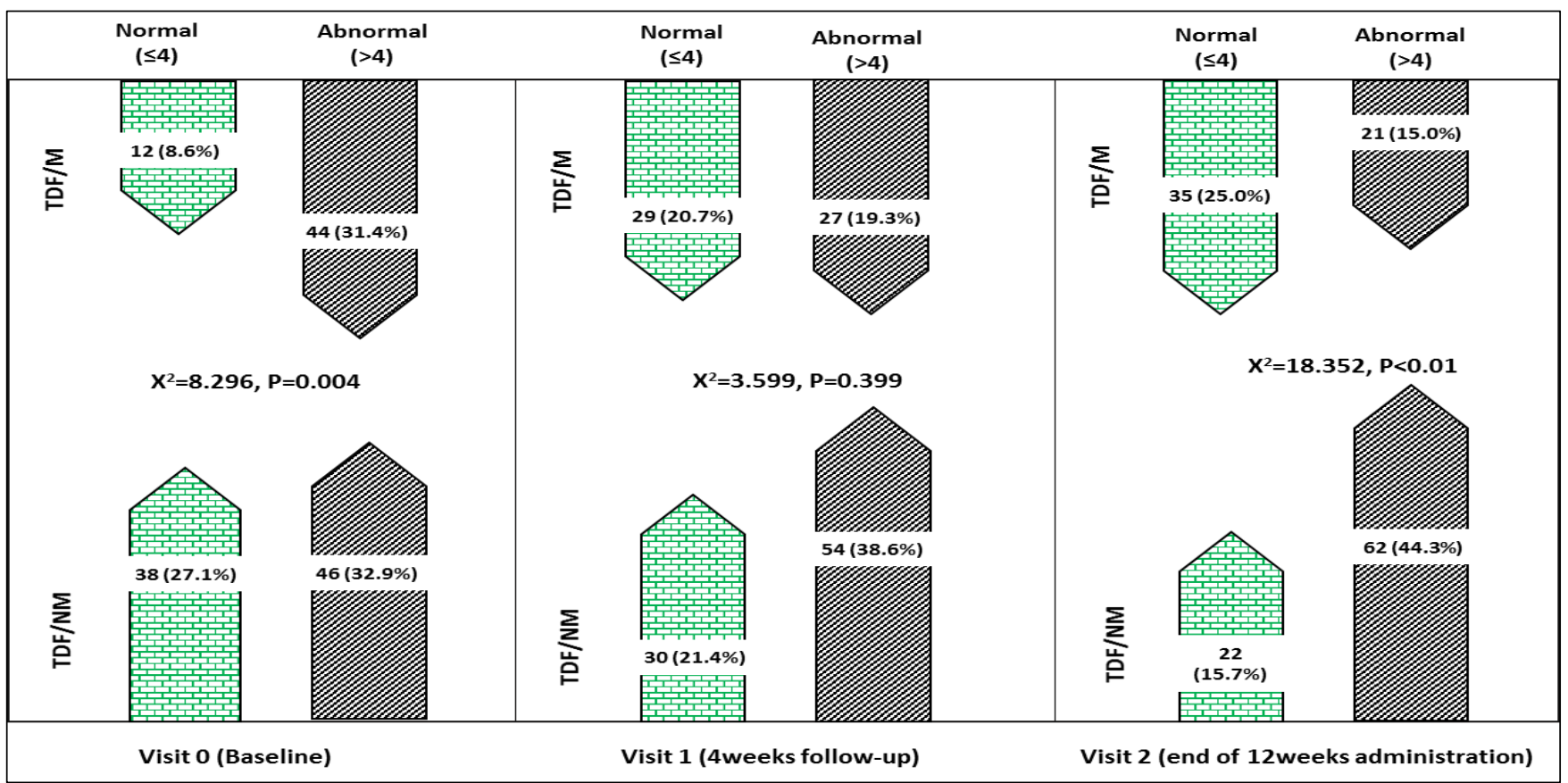

Figure 3: TC/HDL-C ratio cutoff distribution of HIV patients on TDF-M and TDF-NM at the various visits. 


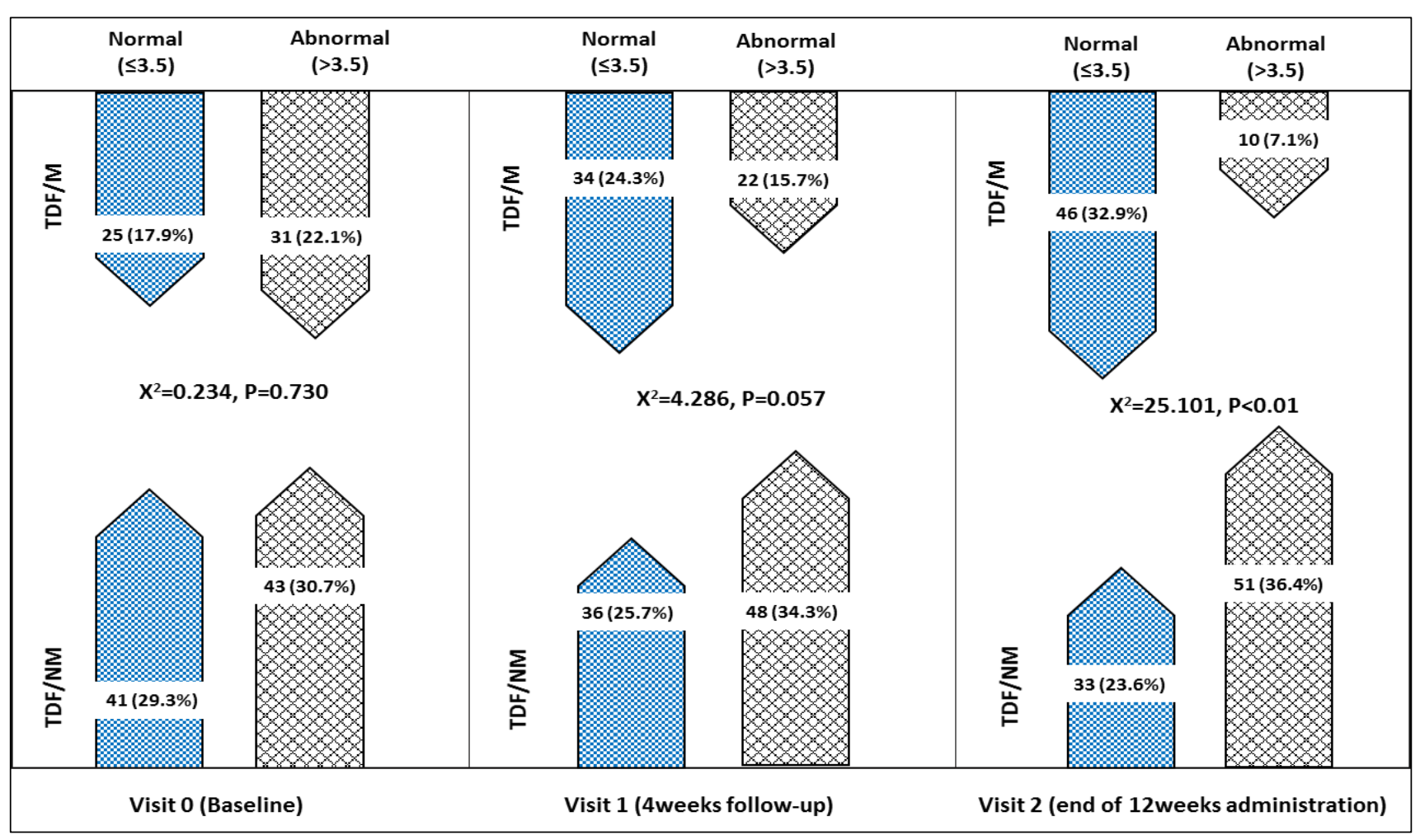

Figure 4: LDL/HDL-C ratio cut off distribution of HIV patients on TDF-M and TDF-NM at the various visits.

The atherogenic lipid indices cut off values showed that TDF-NM group had a steady proportion $(52.1 \%$ at visit 0 , $54.3 \%$ at visit 1 and $53.6 \%$ visit 2 ) of patients at risk of CVD using the Log (TG/HD) index, while the TDF-M had a decrease from $33.6 \%$ at visit 0 to $20.0 \%$ at visit 2 . The reduction trend was statistically significant at visit 2 $\left(\chi^{2}=26.67, \mathrm{P}<0.001\right)$ but not $1\left(\chi^{2}=2.933, \mathrm{P}=0.07\right)$ (Figure 2 ). The proportion of patient with abnormal TC/HDL-C ratio in the TDF-M group, slightly significantly reduced through visit $0(40 \%)$, visit $1(20.7 \%)$ to visit $2(15 \%)$ while a slight increase was observed in the TDF-NM $(27.1 \%$ at visit $0,38.6 \%$ at visit 1 and $44.3 \%$ at visit 2$)$. The distribution was significant at visit $0\left(\chi^{2}=8.296, \mathrm{P}=0.04\right)$ and visit $2\left(\chi^{2}=18.352, \mathrm{P}<0.001\right)$ but not visit $1\left(\chi^{2}=3.559\right.$, $\mathrm{P}=0.080$ ) (Figure 3).

LDL-C/HDL-C cut off values for normalcy in the TDF-M group significantly increased from $17.9 \%$ at baseline to $32.9 \%$ at visit 2 (12 weeks after administration) while the TDF-NM group had a steady abnormally distributed C/HDL-C cut off values through the experiment, visit 0 $(30.7 \%)$, visit $1(34.3 \%)$ and visit 2 (36.4\%). The difference in proportion was significant at visit 2 $\left(\chi^{2}=25.101, \mathrm{P}<0.001\right)$ (Figure 4).

\section{DISCUSSION}

The results showed that $73.5 \%$ of patients were at various levels of risk (ranging from low, medium to high risk using the Log (TG/HDL-C) index of developing cardiovascular diseases (CDs). While the cholesterol ratios TC/HDL-C and LDL-C/HDL-C picked abnormal ratios of $32.9 \%$ and $30.7 \%$ at baseline respectively. It should be noted that cardiovascular risk increased in relation to TC/HDL-C levels, regardless of TC or LDL cholesterol levels with a better predictive capability when compared to standalone univariate biomarkers. ${ }^{28-30}$ The most important relationship between HDL and LDL is the relative quantity of either one that circulates in the bloodstream. Therefore, HIV patient on ART need to maintain a high HDL and low levels of LDL to reduce the chance of coronary heart disease or CVDs. ${ }^{31,32}$ Boden WE also suggested that decreased level of HDL-C is an independent risk factor for coronary heart disease (CHD) as elevated levels of triglycerides (TG) contribute to the reoccurrence of CHDs in these patients. ${ }^{33,34}$ However, the inverse relationship between HDL-C and TG has been established in hypertriglyceridemic conditions. ${ }^{35}$

Although human studies on the effect of Moringa on atherogenic lipid indices are scarce, however, this study observed that most of the subject at risk of CDs (using the Log (TC/HDL-C) index) was at the lower limits range of 4.1-4.9 and this contributed to over $60 \%$ of the cases in this study. However, it must be noted that the findings of this study have not categorically established dyslipidemic abnormalities but has thrown a pointer to the possibility of HIV-patients on ART developing CVDs. ${ }^{10,11}$ The influence Moringa supplement had on TC/HDL-C and LDL$\mathrm{C} / \mathrm{HDL}-\mathrm{C}$ were most significant at the end of the 12 weeks 
of administration (visit 2) as there was a marked reduction in the proportion of patients with abnormal TC/HDL-C and LDL-C/HDL-C levels. There is no doubt that lipoprotein indices or ratios are indicators of dyslipidemia, however, the prevalence could differ between sexes as well as across regions. ${ }^{32,36}$ This postulation is not surprising as experimental reports suggest that a co-factorial effect of ART therapy and the HIV infection could have predisposed patients to dyslipidemia, while the different antiretroviral therapies, feeding pattern, and lifestyle could additionally play a role. ${ }^{32,37}$

Generally, clinical animal experimentation on the effect of Moringa plant parts on the lipid profile and indices have been researched with reports of positive antihypertensive, hypolipidemic and hypocholesterolaemic effects which has been attributed to the presence of $\beta$-sitosterol. ${ }^{18,38,39,40}$

\section{CONCLUSION}

There was a high proportion of HIV patients on TDF based regime at risk of CDs, which were found to have values at the borderline of normalcy and abnormality; suggesting the need for broader classification. The administration of Moringa supplement proved to be effective in ameliorating the dyslipidemic state of patients on TDF based antiretroviral regimen; thus, strengthen the advocacy for the inclusion as a dietary supplement for HIV management.

\section{Funding: No funding sources}

Conflict of interest: None declared

Ethical approval: The study was approved by the Research Ethics Committee of the University of Port Harcourt, Nigeria (reference number $U P H / R \& D / R E C / 04$ )

\section{REFERENCES}

1. Nath A. Neurologic complications of human immunodeficiency virus infection. Continuum (MinneapMinn). 2015;21(6):1557-6.

2. World Health Organization (WHO). Global health sector strategy on HIV/AIDS 2011-2015. Geneva: World Health Organization, 2015. Available at https://www.who.int/hiv/pub/hiv_strategy/en/.

Accessed 12 April 2016.

3. Carr A, Samaras K, Thorisdottir A, Kaufmann GR, Chisholm DJ, Cooper DA. Diagnosis, prediction, and natural course of HIV-1 protease-inhibitor-associated lipodystrophy, hyperlipidaemia, and diabetes mellitus: a cohort study. Lancet. 1999; 353(9170): 2093-9.

4. Currier JS. Epidemiology of cardiovascular disease and risk factors in HIV-infected patients. Up to date. Walter Kluwer, 2015. Available at: https://www.uptodate.com/contents/epidemiology-ofcardiovascular-disease-and-risk-factors-in-hivinfected-patients. Accessed 12 April 2016.

5. Carr A, Samaras K, Burton S. A syndrome of peripheral lipodystrophy, hyperlipidaemia and insulin resistance in patients receiving HIV protease inhibitors. AIDS. 1998;12:F51.
6. Barbaro G. Highly active antiretroviral therapyassociated metabolic syndrome: pathogenesis and cardiovascular risk. Am J Ther. 2006;13(3):248-60,

7. Grinspoon SK, Grunfeld C, Kotler DP. State of the science conference: initiative to decrease cardiovascular risk and increase quality of care for patients living with HIV/AIDS: executive summary. Circulation. 2008;118(2):198-210.

8. Grover SA, Coupal L, Gilmore N, Mukherjee J. Impact of dyslipidemia associated with highly active antiretroviral therapy (HAART) on cardiovascular risk and life expectancy. Am J Cardiol. 2005;95(5):586-91.

9. Currier JS, Lundgren JD, Carr A. Epidemiological evidence for cardiovascular disease in HIV-infected patients and relationship to highly active antiretroviral therapy. Circulation. 2008;118(2):29-35.

10. Dobiasova M. AIP-atherogenic index of plasma as a significant predictor of cardiovascular risk: from research to practice. Inter Med. 2006;52(1):64-71.

11. Dobiásová M, Frohlich J. The plasma parameter log (TG/HDL-C) as an atherogenic index: correlation with lipoprotein particle size and esterification rate in apoB-lipoprotein-depleted plasma (FER(HDL)). Clin Biochem. 2001;34(7):583-8.

12. Castelli WJ, Garrison RJ, Wilson PWF, Abbot RD, Kalousdian S, Kannel WB. Incidence of coronary heart disease and lipoprotein cholesterol levels. The Framingham Study. JAMA. 1986;256:2835-8.

13. Assmann G, Schulte H. The prospective cardiovascular münster (PROCAM) study: prevalence of hyperlipidemia in persons with hypertension and/or diabetes mellitus and the relationship to coronary heart disease. Am Heart J. 1988;116(6 Pt 2):1713-24.

14. Grover SA, Palmer CS, Coupall L. Serum lipid screening to identify high risk individuals for coronary death: the results of the Lipid Research Clinics prevalence cohort. Arch Intern Med. 1994;154:67984.

15. The West of Scotland Coronary Prevention Study Group (WOSCOPS): baseline risk factors and their association with outcome in the West of Scotland coronary prevention study. Am J Cardiol. 1997;79:756-62.

16. Gotto A, Whitney E, Stein EA, Shapiro DR., Clearfield M, Weis S, et al. Relation between baseline and on-treatment lipid parameters and first acute major coronary event in the air force/texas coronary atherosclerosis prevention study (AFCAPS/TexCAPS). Circulation. 2000;101:477-84.

17. Pedersen TR, Kjekshus J, Pyörälä K, Olsson AG, Cook TJ, Musliner TA, et al. Effect of simvastatin on ischemic signs and symptoms in the Scandinavian simvastatin survival study (4S). Am J Cardiol. 1998;81(3):333-5.

18. Mehta K, Balaraman R, Amin AH, Bafna PA, Gulati OD. Effect of fruits of Moringa oleifera on the lipid profile of normal and hypercholesterolaemic rabbits. J Ethnopharmacol. 2003;86(2-3):191-5.

19. Gunjal AM, Shah AS, Wakade AS, Juvekar AR. Protective effect of aqueous extract of Moringa 
oleifera Lam. stem bark on serum lipids, marker enzymes and heart antioxidants parameters in isoproterenol-induced cardiotoxicity in Wistar rats. Ind J Nat Prod Res. 2010;1(4):485-92.

20. Council for International Organizations of Medical Sciences (CIOMS). International Ethical Guidelines for Health-related Research Involving Humans. Fourth Edition. Geneva. 2016. Available at: https://cioms.ch/wp-content/uploads/2017/01/WEBCIOMS-EthicalGuidelines.pdf. Accessed 7 November 2016.

21. Junod SW, Beaver WT. FDA and clinical drug trials: a short history. US Food and Drug Administration, 2013. Available at: http://www.fda.gov/AboutFDA/WhatWeDo/History /Overviews/ucm304485.htm. Accessed 7 May 2016.

22. Schulz KF, Altman DG, Moher D. CONSORT 2010 Statement: updated guidelines for reporting parallel group randomized trials. Brit Med J. 2010;340:c332.

23. Chalmers TC, Smith H Jr, Blackburn B, Silverman B, Schroeder, B, Reitman, D, et al. A method for assessing the quality of a randomized control trial. Control Clin Trials. 1981;2(1):31-49.

24. Ranjith G. Interferon- $\alpha$-induced depression: when a randomized trial is not a randomized controlled trial. Psychother Psychosom. 2005;74(6):387.

25. Li LM, Ye DQ, Zhan SY. Epidemiology. 6th ed. Beijing: People's Medical Publishing House; 2007.

26. Zhong B. How to calculate sample size in randomized controlled trial. J Thorac Dis. 2009;1(1):51-4.

27. Nwagha U, Ikekpeazu E, Ejezie F, Neboh E, Maduka I. Atherogenic index of plasma as useful predictor of cardiovascular risk among postmenopausal women in Enugu, Nigeria. Afr J Health Sci. 2010;10(3):248-52.

28. Nam BH, Kannel WB, D'Agostino RB. Search for an optimal atherogenic lipid risk profile: from the Framingham Study. Am J Cardiol. 2006;97(3):372-5.

29. Millán J, Pintó X, Muñoz A, Zúñiga M, Rubiés-Prat J, Pallardo LF, et al. Lipoprotein ratios: Physiological significance and clinical usefulness in cardiovascular prevention. Vasc Health Risk Manag. 2009;5:757-65.

30. Criqui MH, GolomBA. Epidemiologic aspects of lipid abnormalities. Am J Med. 1998;105(1A): 48S-57S.

31. Guaraldi G, Stentarelli C, Zona S, Orlando G, Carli F, Ligabue $\mathrm{G}$, et al. Lipodystrophy and anti-retroviral therapy as predictors of sub-clinical atherosclerosis in human immunodeficiency virus infected subjects. Atherosclerosis. 2010;208(1):222-7.
32. Nsagha DS, Assob JCN, Njunda AL, Tanue EA, Kibu OD, Ayima CW, et al. Risk factors of cardiovascular diseases in HIV/AIDS patients on HAART. Open AIDS J. 2015;9:51-9.

33. Boden WE. High-density lipoprotein cholesterol as an independent risk factor in cardiovascular disease: assessing the data from Framingham to the veterans affairs high-density lipoprotein intervention trial. Am J Cardiol. 2000;86(12A):19L-22L.

34. Assmann G. Pro and con: High-density lipoprotein, triglycerides, and other lipid subfractions are the future of lipid management. Am $\mathrm{J}$ Cardiol. 2001;87(5A):2B-7B.

35. Brewer HB Jr. Hypertriglyceridemia: changes in the plasma lipoproteins associated with an increased risk of cardiovascular disease. Am J Cardiol. 1999;83(9B):3F-12F.

36. Armstrong C, Liu E, Okuma J, Spiegelman D, Guerino C, Njelekela M, et al. Dyslipidemia in an HIV-positive antiretroviral treatment-naive population in Dar es GaSalaam, Tanzania. J Acquir Immune Defic Syndr. 2011;57(2):141-5.

37. Bloomfield GS, Hogan JW, KeterA, Sang E, Carter EJ, Velazquez EJ, et al. Hypertension and obesity as cardiovascular risk factors among HIV seropositive patients in Western Kenya. PLoS One. 2011;6(7):e22288

38. Dangi SY, Jolly CI, Narayanan S. Antihypertensive activity of the total alkaloids from the leaves of Moringa oleifera. Pharm Biol. 2002;40:144-8.

39. Rouhi-Broujeni H, Heidarian E, DarvishzadehBoroojeni P, Rafieian-Kopaei M, Gharipour M. Lipid lowering activity of Moringa pergerina seeds in rat: a comparison between the extract and atorvastatin. J Biol Sci. 2013;8(5):150-4.

40. Bais S, Singh SG, Sharma R. Antiobesity and hypolipidemic activity of Moringa oleifera leaves against high fat diet-induced obesity in rats. Adv Biol. 2014(162914):9.

Cite this article as: Anyanwu $\mathrm{CF}$, Obianime WA, Siminialayi IM, Aigbogun EO. Evaluating the effects of Moringa oleifera on atherogenic lipoprotein indices of HIV infected Nigerian adults on tenofovirbased antiretroviral regimen. Int J Basic Clin Pharmacol 2019;8:1312-9. 